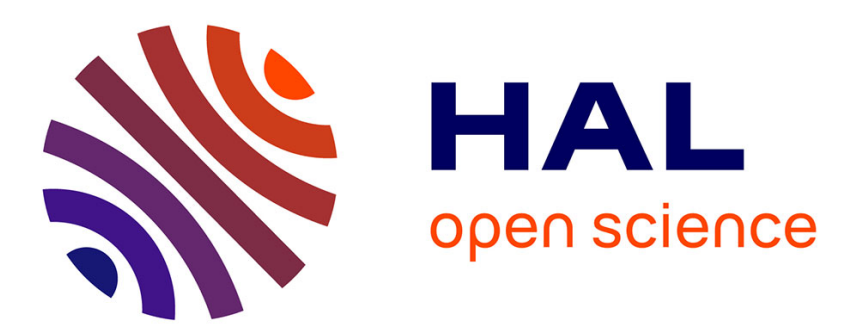

\title{
Study of the Combined Effects of the Air-Gap Transfer for Maxwell Tensor and the Tooth Mechanical Modulation in Electrical Machines
}

Raphael Pile, Yvonnick Le Menach, Jean Le Besnerais, Guillaume Parent

\section{- To cite this version:}

Raphael Pile, Yvonnick Le Menach, Jean Le Besnerais, Guillaume Parent. Study of the Combined Effects of the Air-Gap Transfer for Maxwell Tensor and the Tooth Mechanical Modulation in Electrical Machines. IEEE Transactions on Magnetics, 2020, 56 (1), pp.1-4. 10.1109/TMAG.2019.2948228 . hal-03197880

\section{HAL Id: hal-03197880 \\ https://hal-univ-artois.archives-ouvertes.fr/hal-03197880}

Submitted on 27 Apr 2021

HAL is a multi-disciplinary open access archive for the deposit and dissemination of scientific research documents, whether they are published or not. The documents may come from teaching and research institutions in France or abroad, or from public or private research centers.
L'archive ouverte pluridisciplinaire HAL, est destinée au dépôt et à la diffusion de documents scientifiques de niveau recherche, publiés ou non, émanant des établissements d'enseignement et de recherche français ou étrangers, des laboratoires publics ou privés. 


\title{
Study of the Combined Effects of the Air-Gap Transfer for Maxwell Tensor and the Tooth Mechanical Modulation in Electrical Machines
}

\author{
Raphaël Pile*†‡, Yvonnick Le Menach ${ }^{\dagger}$, Jean Le Besnerais* and Guillaume Parent ${ }^{\ddagger}$ \\ *EOMYS ENGINEERING, Lille-Hellemmes 59260, France, raphael.pile@eomys.com \\ ${ }^{\dagger}$ Univ. Lille, Arts et Metiers ParisTech, Centrale Lille, HEI, EA 2697 - L2EP -Laboratoire d'Electrotechnique \\ et d'Electronique de Puissance, F-59000 Lille, France \\ $\ddagger$ Univ. Artois, EA 4025, Laboratoire Systèmes Électrotechniques et Environnement (LSEE), F-62400 Béthune, France
}

\begin{abstract}
The Maxwell Tensor (MT) method is widely used to compute global forces or local surface forces for vibroacoustic design of electrical machines under electromagnetic excitation. In particular the air-gap Maxwell Tensor method is based on a cylindrical shell in the middle of the air-gap. This paper proposes to quantify the differences between the air-gap MT and the magnetic force wave experienced by the stator. In particular the air-gap to stator transfer and the tooth mechanical modulation effects are studied. A new formula is proposed to extend the tooth modulation effect to tangential forces. A numerical application is performed with a turbo-alternator to illustrate the respective and combined effects of both phenomena. The paper highlights that the tooth mechanical modulation is relevant even for electrical machines with a high number of teeth. Additionally the combination of the two phenomena has a clear impact on the calculated surface force. Therefore, it is recommended to take into account the air-gap transfer for any study of the tooth mechanical modulation effect.
\end{abstract}

\section{INTRODUCTION}

Maxwell Tensor (MT) is widely used to compute the magnetic forces that apply to electrical machines subjected to electromagnetic excitation. In particular the air-gap MT method is based on a cylindrical surface in the middle of the air-gap. In general the air-gap MT is used by electrical machine designers to compute accurately the global electromagnetic torque waveform.

This technique has been extended to the study of local magnetic forces experienced by the outer structure (generally the stator) for vibro-acoustic studies [1]: it gives an accurate harmonic content and it can be used to troubleshoot the electromagnetic vibrations. In order to improve the accuracy of this method, recent works [2,3] suggest the use of transfer coefficients which allows to compute surface forces at stator bore radius based on the air-gap surface forces: magnetic field in the middle of the air-gap contains less numerical noise, which reduces the risk of incorrectly exciting natural frequencies. Moreover, analytical magnetic flux models are limited to the middle of the air-gap. Although the air-gap MT is a good approximation of magnetic forces for small air-gaps, its application to topologies such as turbo-alternators with relatively wide air-gaps could lead to significant errors for magnetic force calculations.

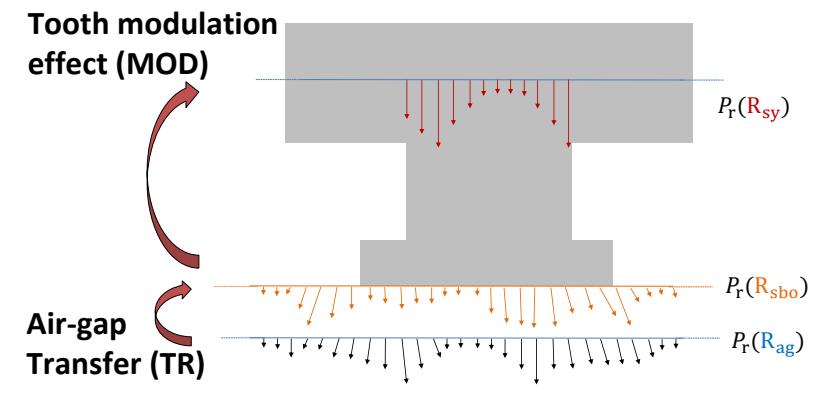

Fig. 1. Magnetic surface force equivalent spectrum from air-gap to yoke

Moreover, recent publications [4,5] are looking for an equivalent magnetic surface force applied on the stator yoke neutral fiber as illustrated in Fig.1. This equivalent force must have the same mechanical response as the air-gap surface force applied on teeth tips. The main phenomenon is that high spatial force wavenumbers at teeth tips are experienced as low wavenumbers at yoke level [4]-[6].

The main motivation of the paper is to improve the accuracy of vibroacoustic simulations based on cylindrical shell structural models of electrical machines. In particular, the paper aims at estimating tangential force contribution to the overall vibration based on the knowledge of the radial force response. The use of analytic mechanical model requires to calculate the equivalent surface force applied on the yoke. Even with numerical simulations such as Finite Element Analysis (FEA), the knowledge of this equivalent force could be useful to diagnose the origin of electromagnetic vibration in electrical machines at early design stage. For this purpose, this paper discusses the main phenomena which could alter the surface force signal between the air-gap and the yoke and two complementary solutions are discussed.

As an application example, a numerical simulation is performed for a turbo-alternator topology. This topology is interesting because it has a relatively high number of teeth and a large air-gap: air-gap width is the main parameter for air-gap transfer [7], while the number of teeth is the main parameter for tooth modulation effect $[4,6]$. 


\section{Application of MaXwell Tensor}

The magnetic flux density $\mathbf{B}$ is related to the magnetic field $\mathbf{H}$ by $\mathbf{B}=\mu(B) \mathbf{H}$ in an incompressible linearly magnetizable media. Then the magnetic stress tensor reduces to the following form [8]:

$$
\mathbf{T}_{\mathrm{m}}=-\mu \frac{\mathbf{H} \cdot \mathbf{H}}{2} \mathbf{I}+\mu \mathbf{H} \otimes \mathbf{H}
$$

with I the identity tensor. Applying Stoke's theorem along a closed boundary $\Gamma$ including a volume $\mathrm{V}$ gives the total magnetic force $\mathbf{F}_{\mathrm{m}}$ acting on this volume. For electrical machines, it is often applied on a cylindrical surface in the middle of the air-gap - radius $R_{a g}$ - as in Fig. 2 [1,9,10]:

$$
\mathbf{F}_{\mathrm{m}}=\int_{\mathrm{V}} \nabla\left(\mathbf{T}_{\mathrm{m}}\right) \mathrm{dV}=\oint_{\Gamma}\left(-\frac{\mu_{0}}{2} H^{2} \mathbf{n}+\mu_{0} H_{\mathrm{n}} \mathbf{H}\right) d \Gamma
$$

with $\mathbf{n}$ the local normal to the boundary $\Gamma$ and $H_{\mathrm{n}}$ the scalar product between $\mathbf{H}$ and $\mathbf{n}$. The air-gap surface force method assumes the term under the integral to be the magnetic surface force density. Developing this term in the polar coordinate system leads to:

$$
\begin{aligned}
P_{\mathrm{r}}\left(\mathrm{R}_{\mathrm{ag}}, \theta\right) & =-\frac{1}{2 \mu_{0}} B_{\mathrm{r}}\left(\mathrm{R}_{\mathrm{ag}}, \theta\right)^{2}-\frac{\mu_{0}}{2} H_{\theta}\left(\mathrm{R}_{\mathrm{ag}}, \theta\right)^{2} \\
P_{\theta}\left(\mathrm{R}_{\mathrm{ag}}, \theta\right) & =-B_{\mathrm{r}}\left(\mathrm{R}_{\mathrm{ag}}, \theta\right) H_{\theta}\left(\mathrm{R}_{\mathrm{ag}}, \theta\right)
\end{aligned}
$$

with $P_{\mathrm{r}}$ the radial magnetic surface force density, $P_{\theta}$ the tangential magnetic surface force density, $B_{\mathrm{r}}$ the radial magnetic flux density, and $H_{\theta}$ the tangential magnetic field. For the vibroacoustic study, it is more practical to decompose the force into Fourier series:

$$
\begin{aligned}
P_{\mathrm{r}}\left(\mathrm{R}_{\mathrm{ag}}, \theta\right) & =\sum_{n=-\infty}^{n+\infty} \hat{P}_{\mathrm{r}, n}\left(\mathrm{R}_{\mathrm{ag}}\right) \mathrm{e}^{j n \theta} \\
P_{\theta}\left(\mathrm{R}_{\mathrm{ag}}, \theta\right) & =\sum_{n=-\infty}^{n+\infty} \hat{P}_{\theta, n}\left(\mathrm{R}_{\mathrm{ag}}\right) \mathrm{e}^{j n \theta}
\end{aligned}
$$

with $\hat{P}_{\mathrm{r}, n}$ and $\hat{P}_{\theta, n}$ the radial/tangential complex amplitude.

\section{Methods FOR AIR-GAP MAXWELl TENSOR}

The aim of this section is to present recent methods to compute the magnetic force waves experienced by the stator from the air-gap surface force.

\section{A. Transfer of surface forces}

This study is based on recent research works about transfer coefficients [2,3]: the magnetic field and flux in the middle of the air-gap are more reliable and can be analytically studied to troubleshoot vibroacoustic issues.

The $n^{\text {th }}$ wavenumber of the surface force applying on the stator bore radius $R_{s}$ can be computed from air-gap surface forces at radius $\mathrm{R}_{\mathrm{ag}}$ according to the transfer law for $\hat{P}_{\mathrm{r}, n}$ and $\hat{P}_{\theta, n}$ :

$$
\begin{aligned}
& \hat{P}_{\mathrm{r}, n}\left(\mathrm{R}_{\mathrm{sbo}}\right)=S_{n} \hat{P}_{\mathrm{r}, n}\left(\mathrm{R}_{\mathrm{ag}}\right)+j C_{n} \hat{P}_{\theta, n}\left(\mathrm{R}_{\mathrm{ag}}\right) \\
& \hat{P}_{\theta, n}\left(\mathrm{R}_{\mathrm{sbo}}\right)=S_{n} \hat{P}_{\theta, n}\left(\mathrm{R}_{\mathrm{ag}}\right)-j C_{n} \hat{P}_{\mathrm{r}, n}\left(\mathrm{R}_{\mathrm{ag}}\right)
\end{aligned}
$$

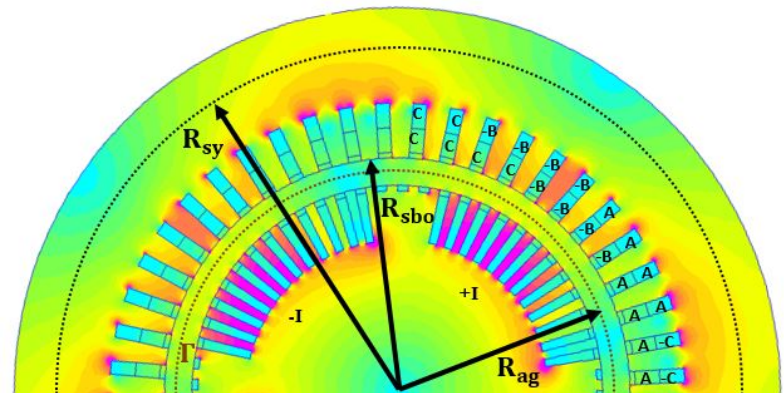

Fig. 2. Turbo-alternator topology with a relatively wide air-gap for numerical study of air-gap transfer and modulation effect.

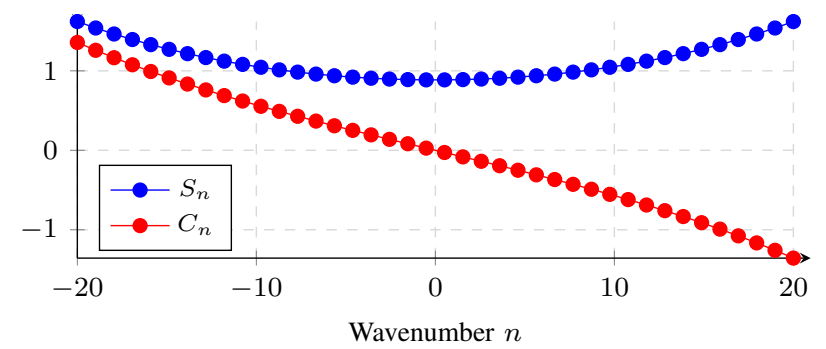

Fig. 3. Transfer coefficients at a fixed relative radius $r=\frac{\mathrm{R}_{\mathrm{ag}}}{\mathrm{R}_{\mathrm{s}}}=0.94$

where $S_{n}$ is the self-transfer coefficient and $C_{n}$ the crosstransfer coefficient:

$$
\begin{aligned}
& S_{n}=\frac{1}{2}\left(\left(\frac{\mathrm{R}_{\mathrm{ag}}}{\mathrm{R}_{\mathrm{sbo}}}\right)^{n+2}+\left(\frac{\mathrm{R}_{\mathrm{ag}}}{\mathrm{R}_{\mathrm{sbo}}}\right)^{-n+2}\right) \\
& C_{n}=\frac{1}{2}\left(\left(\frac{\mathrm{R}_{\mathrm{ag}}}{\mathrm{R}_{\mathrm{sbo}}}\right)^{n+2}-\left(\frac{\mathrm{R}_{\mathrm{ag}}}{\mathrm{R}_{\mathrm{sbo}}}\right)^{-n+2}\right)
\end{aligned}
$$

This transfer law is valid for any topology with a circular air-gap band, in particular for wide air-gap topologies where (3) highly depends on the radius of application. For $n=0$, electromagnetic torque is independent of the radius [7].

In electrical machines, radial force is often much higher than the tangential force for lowest wavenumbers such that the cross-transfer $C_{n}$ can be accurately neglected in (5). However $C_{n}$ is generally neglected as well in (6) which can lead to incorrect estimation of tangential forces [3].

The impact of coefficients $(7,8)$ on the computed magnetic surface force is presented in Fig. 3. $S_{n}$ and $C_{n}$ are polynomials of order $n$ function of $\mathrm{R}_{\mathrm{sbo}} / \mathrm{R}_{\mathrm{ag}}$. Thus the effect of air-gap transfer on the magnetic surface force increases with $n$. It is usually assumed that the lowest wavenumbers are the only ones of vibroacoustic significance. Nevertheless, next section explains how high wavenumbers can contribute significantly to the overall vibration because of the modulation effect.

\section{B. Radial Tooth Mechanical Modulation}

The idea that stator teeth could perform a spatial sampling of magnetic forces is not new [6]: continuous Shannon theorem applies between air-gap surface forces and equivalent yoke surface force. It is called the tooth mechanical modulation effect - or slot aliasing effect - and it can have significant impact on the vibroacoustic behaviour $[4,5]$. 


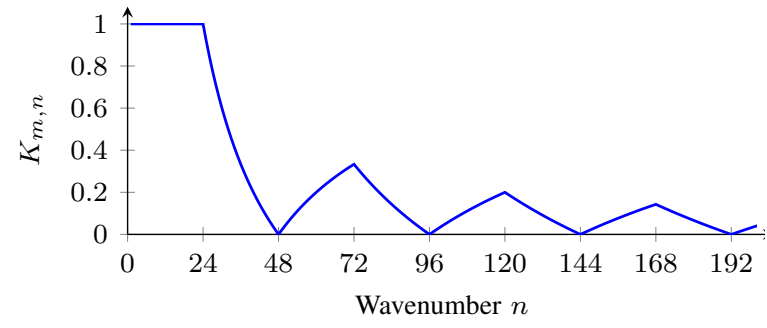

Fig. 4. Modulation coefficient depending on the wavenumber for $Z_{s}=48$

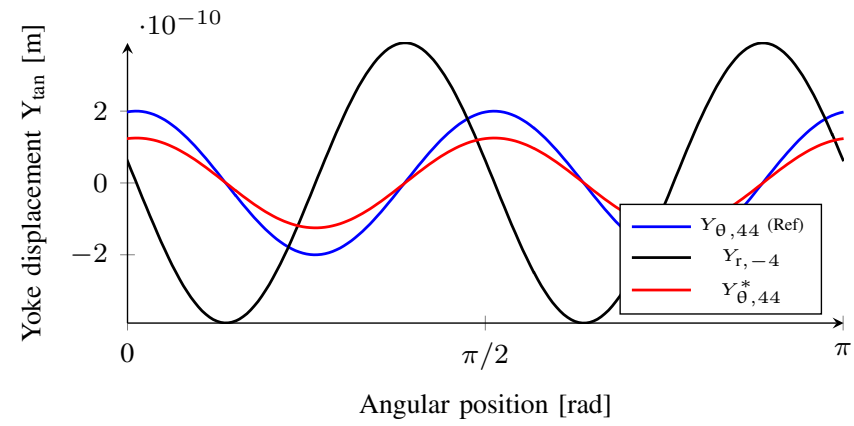

Fig. 5. Comparison of the displacement on the external yoke from tooth tip tangential excitation (at $600 \mathrm{~Hz}$ ): FEA $Y_{\theta, 44}$ vs. modulation $Y_{\theta, 44}^{*}$

Considering a stator with $\mathrm{Z}_{\mathrm{s}}$ teeth, the surface force $\hat{P}_{\mathrm{r}, n}\left(\mathrm{R}_{\mathrm{s}}\right)$ of wavenumber $n$ such that $|n|>\left|\frac{Z_{\mathrm{s}}}{2}\right|$ is modulated into a surface force $\hat{P}_{\mathrm{r}, m}\left(\mathrm{R}_{\mathrm{s}}\right)$ of wavenumber $m$ experienced by the stator yoke such that $m=n-k \mathrm{Z}_{\mathrm{s}}$ with $k \in \mathbb{Z}$ and $|m| \leq\left|\frac{\mathrm{Z}_{\mathrm{s}}}{2}\right|$ [4]. In this paper, the following modulation law is deduced from $[4,5]$ to compute the modulated radial surface force:

$$
\hat{P}_{\mathrm{r}, m}^{\prime}\left(\mathrm{R}_{\mathrm{sy}}\right)=K_{m, n} \hat{P}_{\mathrm{r}, n}\left(\mathrm{R}_{\mathrm{sbo}}\right)
$$

with $K_{m, n}=\frac{m}{n} \sin \left(\frac{n \pi}{Z_{\mathrm{s}}}\right) / \sin \left(\frac{m \pi}{Z_{\mathrm{s}}}\right)$ the modulation coefficient. The main physical interpretation from (9) is that the displacement generated by a wavenumber higher than $\mathrm{Z}_{\mathrm{s}} / 2$ can be deduced from the displacement generated by a wavenumber below $Z_{\mathrm{s}} / 2$. For example, an air-gap force of wavenumber $n=44$ with $\mathrm{Z}_{\mathrm{s}}=48$ contributes to displacement of order $m=44-\mathrm{Z}_{\mathrm{s}}=-4$. The modulation coefficient $K_{m, n}$ is plotted in Fig. 4. The result is symmetric for $n<0$. According to this model, $K_{m, n}=0$ when $n=k Z_{\mathrm{s}}, \forall k \in \mathbb{Z}$. An attempt to solve this issue by taking into account the slot opening is discussed by [5].

\section{Tangential Bending Modulation}

Air-gap tangential surface force also contributes to radial yoke displacements. Indeed tangential surface force on the tooth tip can be modelled by an equivalent radial force on the yoke [11] based on the bending moment of the tooth:

$$
\hat{P}_{\mathrm{r}, n}^{\prime \prime}\left(\mathrm{R}_{\mathrm{sy}}\right)=-2 j \mathrm{Z}_{\mathrm{s}} \frac{\mathrm{R}_{\mathrm{sy}}-\mathrm{R}_{\mathrm{sbo}}}{2 \pi \mathrm{R}_{\mathrm{sy}}} \sin \left(n \pi / \mathrm{Z}_{\mathrm{s}}\right) \hat{P}_{\theta, n}\left(\mathrm{R}_{\mathrm{sbo}}\right)
$$

This paper proposes a combination of (10) with modulation effect (9) to estimate the contribution of high tangential wavenumbers on the yoke radial displacement:

$$
\hat{P}_{\mathrm{r}, m}^{*}\left(\mathrm{R}_{\mathrm{sy}}\right)=K_{m, n} \hat{P}_{\mathrm{r}, n}^{\prime \prime}\left(\mathrm{R}_{\mathrm{sy}}\right)
$$

TABLE I

TURBO-ALTERNATOR PARAMETERS

\begin{tabular}{|c|c|c|}
\hline Parameter & Symbol & Value \\
\hline Number of poles & $\mathrm{p}$ & 4 \\
\hline Number of stator teeth & $\mathrm{Z}_{\mathrm{s}}$ & 48 \\
\hline Ferromagnetic Relative permeability & $\mu$ & 1000 \\
\hline Air gap length & $\mathrm{g}$ & $100[\mathrm{~mm}]$ \\
\hline Machine length & $\mathrm{L}$ & $1000[\mathrm{~mm}]$ \\
\hline Middle air-gap radius & $\mathrm{R}_{\mathrm{ag}}$ & $800[\mathrm{~mm}]$ \\
\hline Stator bore radius & $\mathrm{R}_{\text {sbo }}$ & $850[\mathrm{~mm}]$ \\
\hline Stator yoke height & $\mathrm{H}_{\text {sy }}$ & $350[\mathrm{~mm}]$ \\
\hline Stator tooth length & $\mathrm{H}_{\text {tooth }}$ & $200[\mathrm{~mm}]$ \\
\hline Stator outer radius & $\mathrm{R}_{\mathrm{sy}}$ & $1400[\mathrm{~mm}]$ \\
\hline Stator slot width & $\mathrm{W}_{\mathrm{s}}$ & $50[\mathrm{~mm}]$ \\
\hline Stator current amplitude & $\mathrm{A}, \mathrm{B}, \mathrm{C}$ & $1 e 4[\mathrm{~A}]$ \\
\hline Rotor bore radius & $\mathrm{R}_{\mathrm{rbo}}$ & $750[\mathrm{~mm}]$ \\
\hline Rotor current amplitude & $\mathrm{I}$ & $1600[\mathrm{~A}]$ \\
\hline
\end{tabular}

It means that the displacement generated by a tangential force wavenumber $n$ can be deduced from the displacement generated by a radial force with the wavenumber $m$.

Addition of (9) and (11) allows to build an equivalent radial surface force at the yoke level:

$$
\hat{P}_{\mathrm{r}, m}\left(\mathrm{R}_{\mathrm{sy}}\right)=\hat{P}_{\mathrm{r}, m}^{\prime}\left(\mathrm{R}_{\mathrm{sy}}\right)+\hat{P}_{\mathrm{r}, m}^{*}\left(\mathrm{R}_{\mathrm{sy}}\right)
$$

\section{ApPlication to A TURBo-ALTERnATOR}

In the next sections, simulations are carried out with the electrical turbo-alternator presented in Fig. 2 and Table I.

\section{A. Bending Modulation Validation}

The numerical validation of the formula (11) is performed with mechanical FEA. The mechanical model is loaded on teeth tips with a tangential force wave. The high number of elements per tooth allow to correctly capture the 44 wave excitation. The results are presented in Fig. 5:

- $Y_{\theta, 44}$ is obtained by direct FEA simulation with a unit tangential surface force wave $\hat{P}_{\theta, 44}=\cos (44 \theta)$. It is the reference.

- $Y_{\mathrm{r},-4}$ is obtained by direct FEA simulation with a unit radial surface force wave $\hat{P}_{\mathrm{r}, 4}=\cos (-4 \theta)$.

- $Y_{\theta, 44}^{*}$ is obtained by applying the bending modulation (11) to the result of $Y_{\mathrm{r},-4}$.

It can be observed that the phase of the method (11) is correct, as well as the order of magnitude of the displacement wave amplitude. This observation stays true at any frequency. The model could be improved in order to adjust the amplitude, for example by taking into account the tooth geometry. This would be the matter of future research work.

\section{B. Transfer and Modulation Combination}

The previous sections present several methods denoted TR (5), MOD-Rad (9) and MOD (12) which allow to improve the accuracy and understanding of magnetic force calculation (see Fig. 1) based on the air-gap surface forces (3) denoted AG. The goal of this section is to perform a numerical application of the previous formulas in order to estimate the impact on vibroacoustic results. In particular, the successive application of TR then MOD is called TRMOD. 


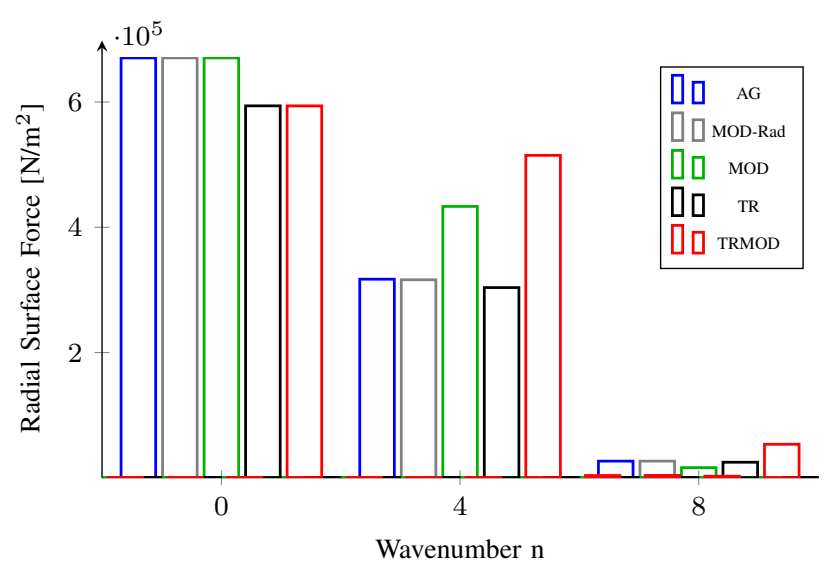

Fig. 6. Comparison of several methods for magnetic surface force to be applied on the teeth tips.

The studied topology is interesting for two reasons:

- The relatively wide air-gap increases the impact of the air-gap transfer.

- The high number of teeth suggests that the modulation effect should stay negligible according to previous research $[4,6]$.

Regarding the time-dependency, the air-gap transfer (5) and the modulation effect (12) are independent of temporal harmonics. Although the vibration spectrum should depend on the excitation's frequency, the goal of this first numerical study is to have a qualitative analysis of the TRMOD method. For these reasons, the simulation is performed using FEMM software [12] at only one time-step. It allows to remove the uncertainty due to time discretization and rotative mesh. For this simulation, the total number of nodes is 176337 and the total number of elements is 352312 . The magnetic field in the air-gap is obtained using the FEMM interpolation [12] feature on a circular contour: the fineness of the mesh size in the air-gap plays an important role in the air-gap surface force calculation on which all the previous transformation TR and MOD are based.

Fig. 6 focuses on magnetic surface force density wavenumbers of interest for vibroacoustic. All previous methods are compared on the turbo-alternator topology. It can be observed that the tooth mechanical modulation neglecting tangential force MOD-Rad has a negligible impact on the surface force spectrum. It can be observed in Fig. 6 that TR transformation alone has little impact on the surface force wavenumbers, in particular the $4^{\text {th }}$ wavenumber. However, it can be observed with TRMOD that the modulation can highly amplify the effect of the transfer law TR. Indeed, the transfer effect mainly has an impact on the highest wavenumbers, which are then modulated on the lowest wavenumbers. This confirms the complementarity of the two methods TR and TRMOD.

The direct use of the above methods for vibroacoustic prediction should be done with caution. Indeed, the purpose of the paper is to investigate new tools to estimate the impact of each phenomena on vibroacoustic results. A rigorous numerical validation with the principle of virtual work [9] will be the subject of future work.s

\section{CONClusion}

In this paper, the application of the Maxwell Tensor in the air-gap for vibroacoustic purpose is discussed. The goal is to obtain an accurate image of the equivalent surface force applying on the yoke which should give the same displacement. For this purpose, two phenomena are studied. The first one is the air-gap transfer, which allow to get surface force applying on the stator bore radius from the airgap surface force. The second one is the modulation effect, which is the transformation of the tooth tip surface force into an equivalent vibroacoustic surface force applying on the yoke. It allows to improve accuracy and reduce mechanical computation time. A new formula is proposed to estimate the contribution of tangential magnetic forces to the overall vibration, based on the radial force response. The formula is interesting for estimating noise with equivalent cylinder mechanical models. The effect of each model was estimated on a numerical application with a turbo-alternator topology. It can be observed that the air-gap transfer amplifies the modulation effect on wavenumbers which have vibroacoustic significance. It is recommended to take into account both phenomena for studying the vibroacoustic impact of high wavenumbers. Future research work will address the issue of slot width. It is also in the scope to perform a comparison of the vibroacoustic predictions with experiments.

\section{REFERENCES}

[1] M. Valavi, A. Nysveen, R. Nilssen, R. D. Lorenz, and T. Rølvåg, "Influence of pole and slot combinations on magnetic forces and vibration in low-speed PM wind generators," IEEE Trans. Magn., vol. 50, no. 5, pp. 1-11, 2014.

[2] R. Pile, G. Parent, E. Devillers, T. Henneron, Y. Le Menach, J. Le Besnerais, and J.-P. Lecointe, "Application Limits of the Airgap Maxwell Tensor," in $C E F C, 2018$.

[3] R. Pile, J. Le Besnerais, G. Parent, Y. Le Menach, E. Devillers, T. henneron, and J.-P. Lecointe, "Transfer Coefficients from Air-gap to Stator Bore Radius for Magnetic Force Wavenumbers -Application to Electrical Machines," Jun. 2019, hal-02168162.

[4] H. Fang, D. Li, R. Qu, and P. Yan, "Modulation effect of slotted structure on vibration response in electrical machines," IEEE Transactions on Industrial Electronics, vol. 66, no. 4, pp. 2998-3007, April 2019.

[5] S. Wang, J. Hong, Y. Sun, and H. Cao, "Analysis of Zeroth Mode Slot Frequency Vibration of Integer Slot Permanent Magnet Synchronous Motors," IEEE Transactions on Industrial Electronics, vol. PP, no. c, pp. 1-1, 2019.

[6] H. Weh, "Zur elektromagnetischen schwingungsanregung bei asynchronmaschinen," ETZ-A, vol. 85, pp. 193-197, 1964.

[7] R. Pile, E. Devillers, and J. Le Besnerais, "Comparison of Main Magnetic Force Computation Methods for Noise and Vibration Assessment in Electrical Machines," IEEE Trans. Magn., vol. 54, no. 7, pp. 1-13, jul 2018.

[8] R. E. Rosensweig, Ferrohydrodynamics. Cambridge University Press, 1985.

[9] Z. Ren, "Comparison of Different Force Calculation Methods in 3D Finite Element Modelling," IEEE Trans. Magn., vol. 30, no. 5, pp. 34713474, 1994.

[10] J. F. Gieras, C. Wang, J. C. S. Lai, and N. Ertugrul, "Analytical prediction of noise of magnetic origin produced by permanent magnet brushless motors," Proceedings of IEEE International Electric Machines and Drives Conference, IEMDC 2007, vol. 1, pp. 148-152, 2007.

[11] J. Roivainen, "Unit-wave response-based modeling of electromechanical noise and vibration of electrical machines," Ph.D. dissertation, Helsinki University of Technology, 2009.

[12] D. Meeker, "Femm 4.2," User's Manual, 2015. 